\title{
Artikel
}

\section{Het fideicommis en temporele problemen bij plaatsvervulling voor verwachters}

Mr. dr. R.E. Brinkman*

\section{Inleiding}

In dit artikel ga ik in op (de formulering van) plaatsvervullingsclausules voor verwachters van een fideicommissaire erfstelling. ${ }^{1}$ Ik neem daarbij de volgende casus in gedachten. De insteller (hierna: opa) wil zijn vrouw (hierna: oma) tot enig bezwaarde van een fideicommissaire erfstelling benoemen. Hij wil vervolgens dat als oma overlijdt, zijn (enig) kind (hierna: $\mathrm{K}$ ) verwachter is, of, als $\mathrm{K}$ oma niet overleeft, ${ }^{2}$ de afstammelingen van $\mathrm{K}$ als bij wettelijke plaatsvervulling. $\mathrm{K}$ heeft éen kind (het kleinkind van opa, hierna: KK). Het kleinkind van opa heeft zelf ook één kind (het achterkleinkind van opa, hierna: AKK).

In een tekening (figuur 1):
* Mr. dr. R.E. Brinkman is notaris te Hardenberg, docent aan de Rijksuniversiteit Groningen en raadsheer-plaatsvervanger bij het Gerechtshof Arnhem-Leeuwarden.

1. Overigens speelt bij fideicommissaire legaten een soortgelijk probleem.

2. Ik ga niet in op andere situaties waarin plaatsvervulling kan spelen, te weten bij verwerping, vervallenverklaring van het erfrecht en onwaardigheid (vgl. art. 4:12 lid $1 \mathrm{BW}$ ). Verder ga ik niet in op de situatie dat plaatsvervulling ook op een 'eerder aangewezen tijdstip' (bijvoorbeeld bij faillissement van of hertrouwen door de bezwaarde) van toepassing zou kunnen zijn. Niettemin raad ik de notariële praktijk aan daar bij de formulering van de plaatsvervullingsclausules wel op te letten.
Figuur 1

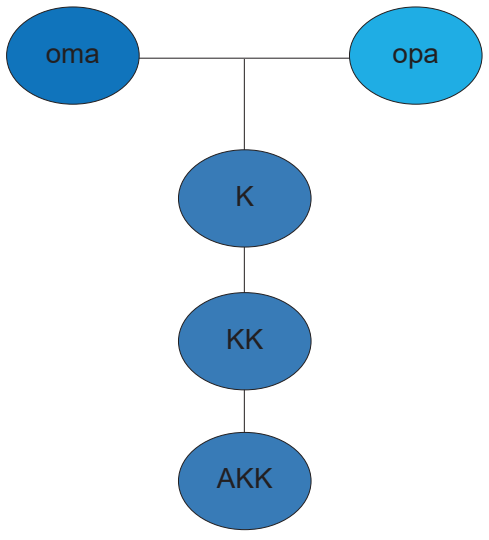

Opa wil verder regelen dat als bij het overlijden van oma geen van zijn afstammelingen verwachter is, zijn familieleden erven en bepaalt daartoe dat als geen van zijn afstammelingen verwachter is, hij tot verwachters benoemt diegenen die zijn erfgenamen bij versterf zouden zijn indien hij op hetzelfde tijdstip als de bezwaarde zou zijn overleden.

\section{Problemen bij de aanwijzing van afstammelingen als plaatsvervullende verwachters}

Als opa overlijdt, is oma enig bezwaarde. Op dat moment is $\mathrm{K}$ de primaire verwachter. In de interne verhouding tussen de bezwaarde en de verwachter kan $\mathrm{K}$ de bevoegdheden uitoefenen die voortvloeien uit de 
overeenkomstige toepassing van de vruchtgebruikbepalingen (art. 4:138 lid 2 jo. titel 3.8 van het Burgerlijk Wetboek (BW)). ${ }^{3}$ Tot zover is er niets aan de hand. De vraag rijst echter wat er gebeurt als $\mathrm{K}$ vóór oma overlijdt. In dat geval komt KK als primaire verwachter in beeld. Ook dan is er nog niets aan de hand. Maar wat nu als ná het overlijden van $K$, maar voor het overlijden van oma, ook KK komt te overlijden? Is AKK dan verwachter? In de plaatsvervullingsclausule die in de inleiding is genoemd, lijkt alleen $\mathrm{KK}$ als verwachter te zijn aangewezen en niet ook AKK. Immers, er staat dat als K oma niet overleeft, de afstammelingen van $K$ als bij wettelijke plaatsvervulling verwachter worden. Op het moment dat $\mathrm{K}$ overlijdt, was dat enkel KK. Dat was anders geweest als $\mathrm{KK}$ reeds vóór $\mathrm{K}$ (en vóór oma) was overleden. In dat geval zou AKK als plaatsvervuller voor $\mathrm{K}$ optreden.

Toch zou ik hier, met enig soepel juridisch gemoed, willen aannemen dat het de bedoeling van opa is geweest om AKK als verwachter aan te wijzen in het bedoelde geval dat KK ná het overlijden van $K$, maar vóór het overlijden van oma, overlijdt. Het probleem zit hier in de periode hangende de voorwaarde. Waar bij een 'gewone plaatsvervulling' slechts één moment (te weten het overlijden van de erflater) in aanmerking wordt genomen om vast te stellen wie als plaatsvervuller opkomt, kan bij het fideicommis sprake zijn van meerdere momenten waarop aangewezen verwachters overlijden.

Om onzekerheid te voorkomen had hij de plaatsvervulling als volgt kunnen formuleren:

a. Ik benoem mijn kind $\mathrm{K}$ tot verwachter.

b. Indien $\mathrm{K}$ oma niet overleeft, benoem ik de afstammelingen van $K$ tot verwachters als ware er op het moment van het overlijden van $K$ sprake van wettelijke plaatsvervulling voor $\mathrm{K}$.

c. Indien ook een onder $\mathrm{b}$ bedoelde afstammeling oma niet overleeft, benoem ik de afstammelingen van eerstbedoelde afstammeling tot verwachters als ware er op het moment van het overlijden van die afstammeling sprake van wettelijke plaatsvervulling voor eerstbedoelde afstammeling.

d. Indien ook een onder c bedoelde afstammeling oma niet overleeft, benoem ik de afstammelingen van de als eerste onder $d$ bedoelde afstammeling tot verwachters als ware er op het moment van het overlijden van de als eerste onder $d$ bedoelde afstamme-

3. Hoewel ook de plaatsvervullende verwachters een voorwaardelijk recht hebben, ga ik ervan uit dat slechts de primaire verwachter (in casu K) de bevoegdheden uit titel 3.8 BW kan uitoefenen. Ik laat hier de vraag onbesproken of de uitgeoefende bevoegdheden 'toegerekend' moeten worden aan de subsidiaire of meer subsidiaire verwachters. Zie daarover R.E. Brinkman, Het fideicommis in de notariële praktijk (diss. Groningen), Den Haag: Boom Juridische uitgevers 2014, par. 1.5.3. Van het in mijn proefschrift ingenomen standpunt dat de subsidiaire of meer subsidiaire verwachters geen voorwaardelijk recht hebben, ben ik, mede naar aanleiding van het arrest van de Hoge Raad van 3 juni 2016 (ECLI:NL:HR:2016:1046, waarover uitgebreid E.F. Verheul, Eigendomsvoorbehoud (diss. Groningen), Deventer: Wolters Kluwer 2017), teruggekomen. ling sprake van wettelijke plaatsvervulling voor de als eerste onder $\mathrm{d}$ bedoelde afstammeling.

Gelet op de maximale duur van een mensenleven en het aantal generaties dat daarmee tussen oma en de verwachter kan zitten, is bovenstaande opsomming waarschijnlijk voldoende. Valt deze uitgebreide formulering wellicht te vatten in een kortere frase? In paragraaf 4 wordt een poging daartoe ondernomen.

\section{Problemen bij de aanwijzing van familieleden als plaatsvervullende verwachters}

Stel dat opa overlijdt zonder achterlating van afstammelingen of dat geen van de afstammelingen van opa (in casu K, KK en AKK) oma overleven. Voor dat geval heeft opa als verwachters aangewezen diegenen die zijn erfgenamen bij versterf zouden zijn indien hij op hetzelfde tijdstip als de bezwaarde zou zijn overleden.

Ik geef een voorbeeld. Stel dat opa geen ouders en slechts één zus heeft (hierna: Z). Z heeft op haar beurt zelf ook een kind (de neef van opa, hierna: $N$ ).

In een tekening (figuur 2):

Figuur 2

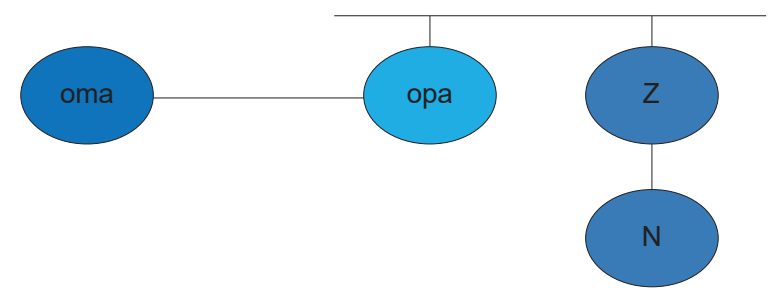

Stel dat Z nog leeft als opa overlijdt. Ik ga ervan uit dat opa wil dat $\mathrm{Z}$ de bevoegdheden die voortvloeien uit de overeenkomstige toepassing van de vruchtgebruikbepalingen kan uitoefenen hangende de voorwaarde. Maar is dat eigenlijk wel zo, als blijkt dat $Z$ twee jaar na opa, maar vóór oma overlijdt? Uit de formulering van de plaatsvervulling lijkt te volgen dat - achteraf bezien slechts $\mathrm{N}$ als verwachter is aangewezen. Onduidelijk is nu of de insteller bedoelt dat, zolang Z leeft, hij als (primaire) verwachter opkomt en dat $N$, zolang Z leeft, subsidiaire verwachter is en pas als $\mathrm{Z}$ overlijdt, tot primaire verwachter 'opklimt'. Oftewel, het eerste probleem is hier: dient de plaatsvervullingsclausule steeds te worden uitgelegd naar het betreffende moment hangende de voorwaarde (als ware de bezwaarde op dat moment overleden)? ${ }^{4}$

4. Ik denk zelf dat eerst $Z$ en (pas) daarna, na het overlijden van $Z, N$ die bevoegdheden mag uitoefenen. Maar dat is dus onzeker, omdat het testament uitgelegd moet worden. Als de bezwaarde bijvoorbeeld zo weinig mogelijk bemoeienis van de verwachter wil, kan ik mij voorstel- 
Een tweede probleem van deze clausule zou kunnen zijn dat er personen blijken te zijn aangewezen die bij het overlijden van opa nog niet bestonden. Artikel 4:56 lid 1 BW stelt als hoofdregel dat men moet bestaan op het ogenblik dat de nalatenschap openvalt, wil men aan een making een recht kunnen ontlenen. Daarop zijn in artikel 4:56 lid 2, 3 en 4 BW uitzonderingen gemaakt. $\mathrm{Nu}$ oma bezwaarde is, zou bij een zuiver fideicommis (waarop art. 4:56 lid 2 en $3 \mathrm{BW}$ van toepassing zijn) $\mathrm{N}$ niet als verwachter kunnen opkomen, als hij bij het overlijden van opa nog niet geboren was (art. 4:56 lid $1 \mathrm{BW}) .{ }^{5} \mathrm{Bij}$ een fideicommis de residuo (waarop art. 4:56 lid 2, 3 en 4 BW van toepassing zijn) zou een dergelijke formulering slechts problemen kunnen opleveren indien er bloedvermanten van de erflater buiten de erfelijke graad of niet-bloedvermanten als verwachters zouden worden benoemd. Dat laatste zal in de praktijk waarschijnlijk niet vaak voorkomen.

Een derde en laatste probleem van deze clausule zou kunnen zijn dat de wet ten tijde van het overlijden van oma er anders uitziet dan bij het overlijden van opa. Onduidelijk is dan wie krachtens die toekomstige wet zouden zijn aangewezen als verwachters.

In paragraaf 4 probeer ik een oplossing te vinden voor de in paragraaf 2 en 3 geschetste problemen.

\section{Oplossing voor de temporele problemen bij de aanwijzing van verwachters}

Stel dat opa het volgende bepaalt:

len dat deze onzekerheid door de bezwaarde wordt aangegrepen om te betogen dat, zolang onduidelijk is wie verwachter is, geen enkele potentiële verwachter de vruchtgebruikbevoegdheden (op grond van art. 4:138 lid 2 BW) kan uitoefenen. Een recente uitspraak van Rechtbank Noord-Nederland van 8 augustus 2018, 7/152681/HA ZA 17-1 (bij het afronden van deze bijdrage (nog) niet gepubliceerd) leert ons dat het alle kanten op kan gaan. (Voor de goede orde wordt vermeld dat de auteur van dit artikel als adviseur van de bezwaarde bij de procedure betrokken was.) In de procedure speelde een fideicommis waarbij een bezwaarde werd aangewezen en bij de benoeming van de verwachters werd opmerkt: 'Indien [de bezwaarde] ten tijde van zijn overlijden geen nakomelingen heeft nagelaten, worden tot zijn verwachters benoemd (...).' De rechtbank oordeelde dat, omdat het recht van de verwachter zelf voorwaardelijk was, de verwachter nog geen vruchtgebruikbevoegdheden mocht uitoefenen. Dit oordeel is mijns inziens onjuist, omdat de verwachter, ook al is zijn voorwaardelijke recht hangende de voorwaarde zelf ook weer voorwaardelijk, vruchtgebruikbevoegdheden heeft zolang zijn recht niet is vervallen. De vervulling van de voorwaarde waarmee het recht van de verwachter zou vervallen (te weten dat de bezwaarde een afstammeling zou nalaten), heeft immers geen terugwerkende kracht, zie art. 3:38 BW. Het toont dat de rechtspraak zo zijn eigen gedachten kan hebben over de positie van de verwachter.

5. Art. 1:2 BW is hierop van toepassing. Daarnaast dient mijns inziens onder 'geborenen' tevens te worden verstaan personen die door adoptie, erkenning en gerechtelijke vaststelling van het ouderschap in een familierechtelijke betrekking tot de erflater komen te staan.
'Ik benoem tot verwachters diegenen die mijn erfgenamen bij versterf zouden zijn indien ik op hetzelfde tijdstip als de bezwaarde zou zijn overleden, voor de delen als $\operatorname{dan}^{6}$ in de wet is bepaald. Hangende de voorwaarde komen steeds die personen als primaire verwachters op, die zouden zijn opgekomen als de bezwaarde op het betreffende moment hangende de voorwaarde zou zijn overleden.

Alleen aan de primaire verwachters komen de bevoegdheden toe die voortvloeien uit de in dit testament genoemde bepalingen en uit de overige bepalingen die voortvloeien uit de overeenkomstige toepassing van de vruchtgebruikbepalingen van titel 3.8 Burgerlijk Wetboek.

Een persoon die krachtens de wet aan deze making geen recht kan ontlenen, is geen verwachter, tenzij deze persoon onder één van de verwachters als bedoeld in artikel 4:56 lid 2, 3 of 4 Burgerlijk Wetboek (of een daarvoor in de plaats komende regeling) wordt begrepen.'

Mijns inziens zijn met een dergelijke formulering de in paragraaf 2 en 3 gesignaleerde problemen opgelost, omdat daarmee duidelijk is wie hangende de voorwaarde primaire verwachter is (en daarmee ook de bevoegdheden mag uitoefenen die voortvloeien uit het testament en de overeenkomstige toepassing van de vruchtgebruikbepalingen). Overlijdt bijvoorbeeld $\mathrm{K}$ hangende de voorwaarde, dan komt met bovenstaande formulering op hetzelfde moment als $\mathrm{K}$ overlijdt KK in beeld als primaire verwachter. Overlijdt vervolgens ook KK hangende de voorwaarde, dan klimt op hetzelfde moment dat KK overlijdt AKK tot primaire verwachter op.

Ook is met een dergelijke formulering duidelijk dat personen die nog niet bestaan bij het overlijden van de insteller en niet vallen onder een van de uitzonderingen van artikel 4:56 lid 2, 3 of $4 \mathrm{BW}$, niet als verwachter kunnen optreden. Tot slot zou een wijziging van de wettelijke erfopvolging tot gevolg hebben dat op dat moment krachtens de nieuwe wet wordt vastgesteld wie als verwachters optreden. ${ }^{7}$

6. Opa kan er ook voor kiezen om te bepalen dat de aanwijzing geschiedt volgens de wet die geldt bij zijn eigen overlijden. Vgl. de tekst die ik als proeve redigeerde in par. 5 van mijn artikel Het fideicommis en de dertigdagenclausule, WPNR 2018/7204.

7. Overigens kan men zich afvragen of dat de erflater wel voor ogen staat, omdat hij toekomstige wetswijzigingen niet kan voorzien (zie ook noot 6). Toch zijn er situaties denkbaar waarin de erflater blij zou zijn met een wetswijziging. Bijvoorbeeld als hangende de voorwaarde de uitzonderingen van art. 4:56 lid 2 en 3 BW worden uitgebreid tot situaties waarin anderen dan afstammelingen van een ouder van de insteller als bezwaarde of verwachter kunnen optreden. Of bijvoorbeeld als de erfelijke graad als bedoeld in art. 4:56 lid 4 BW wordt aangepast tot bijvoorbeeld de twaalfde graad, zoals dat tussen 1838 en 1923 in ons BW gold (in plaats van de huidige zesde graad, art. 4:12 lid 3 BW). 


\section{Nog twee kleine problemen:} aanwas versus plaatsvervulling en commoriënten

Stel dat opa niet één kind $\mathrm{K}$, maar twee kinderen (hierna: K1 en K2) heeft en dat K1 op zijn beurt één kind heeft (opa's kleinkind, hierna: KK1).

In een tekening (figuur 3):

Figuur 3

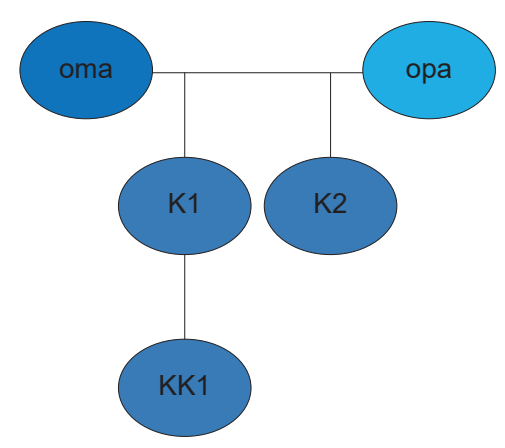

Stel dat opa zijn kinderen K1 en K2 tot verwachters benoemt, met toepassing van de 'wettelijke plaatsvervulling'. Ik vraag mij af wat er gebeurt als K1 na opa, maar vóór oma overlijdt. Is artikel 4:48 $\mathrm{BW}$ dan van toepassing, als gevolg waarvan anwas ten behoeve van K2 plaatsvindt, omdat de beschikking ten opzichte van K1 geen gevolg heeft? Of gaat de plaatsvervulling, op grond van de 'tenzij-clausule' van artikel 4:48 BW, boven de aanwas, als gevolg waarvan KK1 de plaats vervult van $\mathrm{K} 1$ ? Het antwoord hangt mijns inziens af van de vraag per welk moment de plaatsvervulling dient te worden vastgesteld. Is dat het moment van opa's overlijden en leeft K1 dan nog, dan zal geen plaatsvervulling optreden en zal het voorwaardelijke erfdeel aanwassen bij K2. Wordt de plaatsvervulling pas vastgesteld op het moment dat K1 overlijdt, dan gaat de plaatsvervulling (voor KK1) mijns inziens vóór aanwas (ten behoeve van K2). Ook hier blijkt dat een goede formulering, die rekening houdt met de temporele ruimte tussen het overlijden van de insteller en de vervulling van de fideicommissaire voorwaarde, uitlegproblemen kan voorkomen.

Een tweede probleem rijst wanneer de volgorde waarin twee of meer personen zijn overleden niet kan worden bepaald. Artikel 4:2 lid 1 BW bepaalt dan dat die personen geacht worden gelijktijdig te zijn overleden en dat aan de ene persoon geen voordeel uit de nalatenschap van de andere ten deel valt. Maar hoe zit dat als de volgorde waarin twee of meer verwachters zijn overleden niet kan worden bepaald? De insteller zou in zijn testament dan, naar analogie van artikel 4:2 lid $1 \mathrm{BW}$, kunnen bepalen dat die verwachters geacht worden gelijktijdig te zijn overleden en dat an die verwachters geen voordeel uit de nalatenschap van de insteller ten deel valt. Uit de benoeming van de verwachters en uit de daarbij horende plaatsvervullings- en aanwasregeling zou dan moeten voortvloeien wat er gebeurt als de plaatsvervuller of degene ten behoeve van wie aanwas plaatsvindt, tegelijk met de bezwaarde overlijdt.

\section{Conclusie}

Het fideicommis blijft vragen oproepen. Een goede formulering van plaatsvervullingsclausules is van belang om onzekerheid over de uitleg van het testament te voorkomen. Ik raad de praktijk dan ook aan de hiervoor genoemde temporele problemen bij de aanwijzing van plaatsvervullers te vermijden met formuleringen die rekening houden met de tijd die gelegen is tussen het overlijden van de insteller en de vervulling van de fideicommissaire voorwaarde. 